\title{
High tuberculosis treatment success in Kabul, Afghanistan despite high patient transfers out
}

\author{
M. Zhuben, ${ }^{7}$ F.M. Delawer, ${ }^{1}$ A.H. Andar, ${ }^{2}$ F. Salimi ${ }^{3}$ and J. Ngamvithayapong-Yanai ${ }^{4}$
}

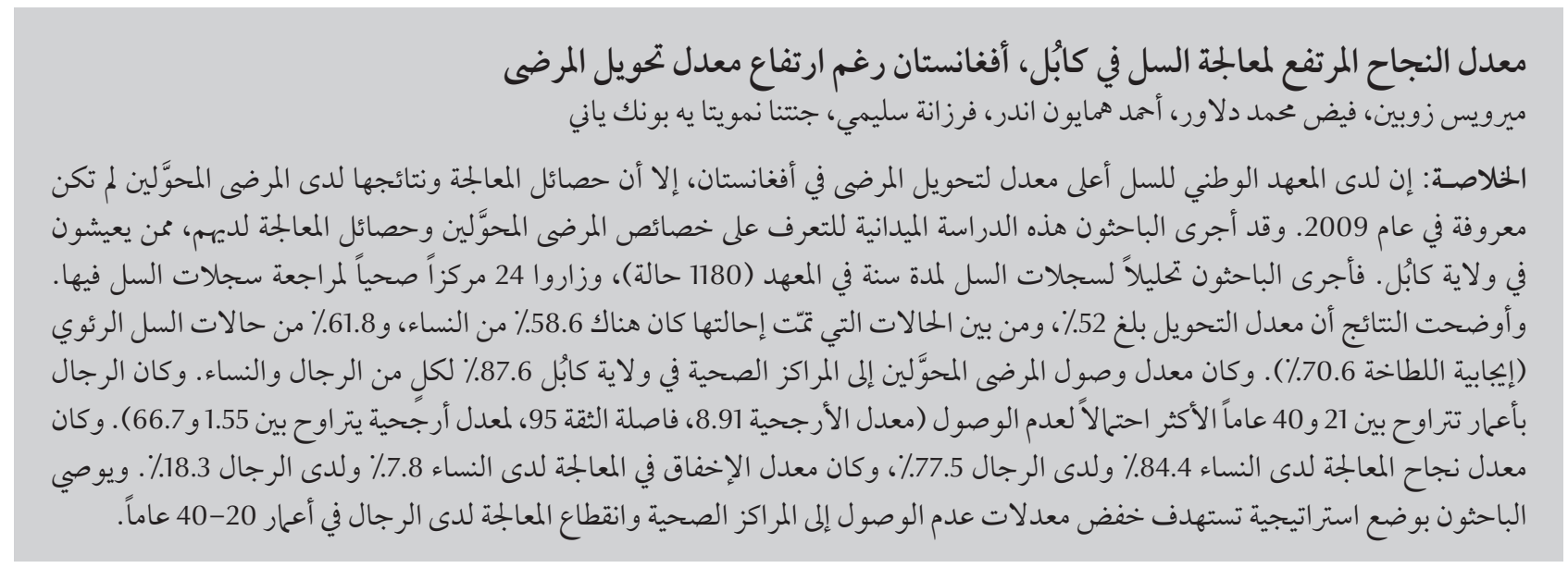

ABSTRACT The National Tuberculosis (TB) Institute has the highest patient transfer-out rate in Afghanistan, but the result and treatment outcome of transferred patients were unknown in 2009. This operational research investigated the characteristics and treatment outcome of all transferred-out patients living in Kabul province. We analysed the 1-year TB register of the Institute ( $n=1180$ cases) and visited 24 health centres to review their TB registers. The results show the transfer-out rate was $52.6 \%$. Of the transferred cases, $58.6 \%$ were women and $61.8 \%$ pulmonary TB cases (smear-positive 70.6\%). The arrival rates of transfer-out patients at health centres in Kabul province were $87.6 \%$ for both men and women. Males aged 21-40 years were the most likely to be nonarrivals $(\mathrm{OR}=8.91 ; 95 \% \mathrm{Cl}: 1.55-66.7)$. Treatment success rates in female and male patients were $84.4 \%$ and $77.5 \%$ respectively and default rates were $7.8 \%$ and $18.3 \%$. Strategies to reduce the non-arrival to health centres and treatment interruption in male patients aged $20-40$ years are warranted.

Fort taux de réussite du traitement de la tuberculose à Kaboul (Afghanistan) malgré un taux élevé de transferts externes de patients

RÉSUMÉ L'Institut national de la tuberculose a le taux de transferts externes de patients le plus élevé en Afghanistan, et les résultats et l'issue du traitement chez les patients transférés étaient inconnus en 2009. La présente recherche opérationnelle a analysé les caractéristiques et l'issue du traitement de tous les patients transférés en externe vivant dans la province de Kaboul. Nous avons analysé le registre des cas de tuberculose de I'Institut pendant un an ( $n=1180$ cas) et avons visité 24 centres de soins de santé afin d'étudier leurs registres de cas de tuberculose. Selon les résultats, le taux de transferts externes était de 52,6\%. Parmi les cas transférés, 58,6\% étaient de sexe féminin et $61,8 \%$ des cas de tuberculose pulmonaire (70,6 \% de frottis positifs). Le pourcentage d'arrivée de patients transférés en externe dans les centres de soins de santé de la province de Kaboul était de $87,6 \%$ pour les hommes comme pour les femmes. Les hommes âgés de 21 à 40 ans représentaient le profil le plus probable de non arrivée $(\mathrm{OR}=8,91$; IC à $95 \%: 1,55-66,7)$. Les taux de réussite du traitement chez les patients de sexe féminin et masculin étaient de $84,4 \%$ et $77,5 \%$ respectivement et les taux d'abandon se montaient à 7,8 \% et $18,3 \%$. Des stratégies visant à réduire la non arrivée du patient aux centres de soins et l'interruption du traitement chez les patients de sexe masculin entre 20 et 40 ans sont requises.

${ }^{\prime}$ Research Unit; National Tuberculosis Control Programme, Kabul, Afghanistan. ${ }^{2}$ Training Department, National Tuberculosis Control Programme, Kabul, Afghanistan. ${ }^{3}$ Public Health Research Directorate, Afghanistan National Public Health Institute, Kabul, Afghanistan. ${ }^{4}$ Research

Department, Research Institute of Tuberculosis, Japan Anti-Tuberculosis Association, Tokyo, Japan (Correspondence to J. Ngamvithayapong-Yanai: jip@loxinfo.co.th; jintanajip@yahoo.com).

Received: 26/02/12; accepted: 30/05/12 


\section{Introduction}

The World Health Organization (WHO) defines "transfer out" as one of the 6 categories for tuberculosis (TB) treatment outcome. A transfer out is a patient who has been transferred to another recording and reporting unit and whose treatment outcome is unknown [1]. It is important to know the transfer result and treatment outcome, especially when patients who are sputum-smear positive are transferred, because without proper TB treatment, infectious TB cases can transmit TB to others. The higher the transfer-out rate, the more important it is to trace the final treatment results to avoid an incomplete evaluation of the treatment [2].

In this paper, we report the transferout results of the National Tuberculosis Institute (NTI) in Kabul, Afghanistan, which reports the highest transfer out rate in Afghanistan.

\section{Methods}

\section{Study setting}

The NTI is the first and biggest TB diagnosis and treatment centre in Kabul. It is reachable by public transport but it takes up to 3 hours and US $\$ 20$ travel cost for people living in the farthest districts of Kabul.

\section{Sample and data collection}

We reviewed the 2009 TB register of the NTI to select the transfer-out patients. In order to know the result of the transfer and TB treatment outcome of the transferred cases, we selected the smear-positive pulmonary $\mathrm{TB}$ patients living in Kabul province and followed up by reviewing the $\mathrm{TB}$ registers at the health centres where the NTI transferred these patients for continued treatment. No patients in this study had received anti-TB medicine from the NTI when they were transferred. Patients whose names and father's names were matched between the NTI register and the health centre registers, and classified as "transfer in" at the health centres, were defined as "arrivals", while patients whose names did not appear in the health centre were defined as "non-arrivals".

The research was approved by the Afghanistan public health institutional review board.

\section{Analysis}

Microsoft Excel 2003 was used to compile data from the NTI register and 2 variables from health centres' registers, i.e. arrival/not arrival and TB treatment outcome. We used Epi Info version 3.5.1 to analyse the frequencies, measures of central tendency and cross-tabulations to compare the proportions. Odds ratios (OR) with $95 \%$ confidence intervals (CI) were used to test the associations of outcomes and the predictors.

\section{Results}

\section{Characteristics of transfer-out patients}

In 2009, the NTI registered a total $1180 \mathrm{~TB}$ patients and transferred 621 patients (52.6\%) back to health centres in 33 provinces (of 34 in the country); about $56 \%$ of them were from Kabul (Figure 1). Of the transferred patients $41.4 \%$ were males and $58.6 \%$ female; the proportions of females were 1.4-2 times higher in most age groups, except for patients < 5 years and $60+$ years old, for whom the male: female ratios were $2: 1$ and

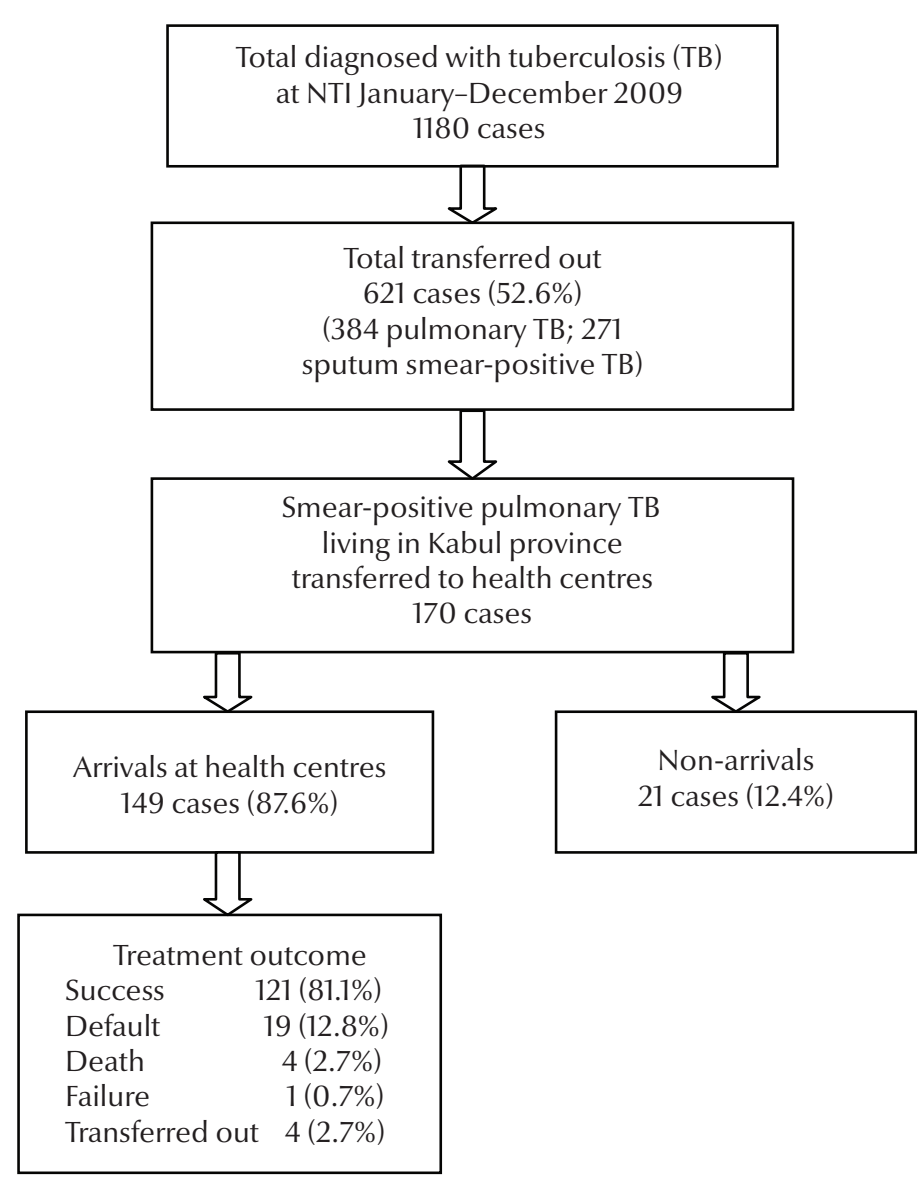

Figure 1 Flow of data collection on patients diagnosed at the National Tuberculosis Institute (NTI) over a 1-year period: numbers transferred out to 24 health centres and results of transfer 


\begin{tabular}{|c|c|c|c|c|c|c|c|c|}
\hline \multirow{3}{*}{$\begin{array}{l}\text { Age of patients } \\
\text { (years) }\end{array}$} & \multicolumn{4}{|c|}{ Males $(n=81)$} & \multicolumn{4}{|c|}{ Females $(n=89)$} \\
\hline & \multicolumn{2}{|c|}{ Arrival } & \multicolumn{2}{|c|}{ Non-arrival } & \multicolumn{2}{|c|}{ Arrival } & \multicolumn{2}{|c|}{ Non-arrival } \\
\hline & No. & $\%$ & No. & $\%$ & No. & $\%$ & No. & $\%$ \\
\hline $10-15$ & 3 & 100.0 & 0 & 0.0 & 5 & 100.0 & 0 & 0.0 \\
\hline $16-20$ & 15 & 93.8 & 1 & 6.2 & 15 & 88.2 & 2 & 11.8 \\
\hline $21-40$ & 22 & 72.8 & 8 & 27.2 & 24 & 82.8 & 5 & 17.2 \\
\hline $41-60$ & 15 & 100.0 & 0 & 0.0 & 28 & 90.3 & 3 & 9.7 \\
\hline$>60$ & 16 & 94.1 & 1 & 5.9 & 6 & 85.7 & 1 & 14.3 \\
\hline Total & 71 & 87.7 & 10 & 12.3 & 78 & 87.6 & 11 & 12.4 \\
\hline
\end{tabular}

1.6:1 respectively (data not shown). Of the transfer-out patients 384 (61.8\%) were pulmonary TB cases and 271 (70.6\%) of these were smear-positive pulmonary $\mathrm{TB}$, with a slightly higher rate in males than females ( $74.5 \%$ versus $68.0 \%)$.

\section{Outcome of transfer-out patients}

Of 621 transfer-out patients, 170 pulmonary TB smear-positive patients living in Kabul were transferred to 24 health centres; $47.6 \%$ were males (Figure 1 and Table 1). A total of 149 patients arrived at health centres, an arrival rate of $87.6 \%$. Male and female patients had almost identical arrival rates ( $87.7 \%$ and $87.6 \%$ respectively) and similar average travelling times between the NTI and the health centres (10.4\% arrived at the health centres within the same day and $43.0 \%$ arrived 1 day later). For the 21 non-arrivals, patients aged $21-40$ years had the highest rate, especially men (Table 1). The OR for non-arrival of male patients aged 21-40 years compared with the other age groups was 8.91 (95\% CI: 1.55-66.7; $P<0.004)$. Females had better treatment outcomes than males, indicated by success rates ( $84.4 \%$ versus $77.5 \%)$ and default rates (7.8\% versus 18.3\%) (Table 2). Half of the default in males occurred in the 20-40 years group, while the other half were patients aged $60+$ years. The female defaulters were distributed in every age group.

\section{Discussion}

Other studies have reported various proportions of transfer-out and treatment outcomes. However, none of the studies analysed the data by sex. Studies from the People's Democratic Republic of Laos [2], Malawi [3] and Morocco [4] reported rates of $16.4 \%$, $13 \%$ and $5.6 \%-8.4 \%$ respectively, which are 3-9 times lower than the transfer-out rate at the NTI. The death rate among smear-positive transferout patients in Malawi was 4 times

\begin{tabular}{lcccc}
\hline $\begin{array}{l}\text { Table } 2 \text { Treatment outcome of transfer-out patients arriving at health centres in } \\
\text { Kabul }\end{array}$ & \multicolumn{2}{c}{$\begin{array}{c}\text { Males } \\
(\boldsymbol{n}=71)\end{array}$} & \multicolumn{2}{c}{$\begin{array}{c}\text { Females } \\
(\boldsymbol{n}=\mathbf{7 8})\end{array}$} \\
\hline Variable & No. & $\%$ & No. & $\%$ \\
& 55 & 77.5 & 66 & 84.4 \\
Success & 13 & 18.3 & 6 & 7.8 \\
Default & 2 & 2.8 & 2 & 2.6 \\
Death & & 0.0 & 1 & 1.3 \\
Failure & 1 & 1.4 & 3 & 3.9 \\
Transferred out & & & & \\
\hline
\end{tabular}

higher than our study, presumably due to the high prevalence of HIV infection. However, the default rate was only $1 \%$, which is 12 times less than in our study. The study in People's Democratic Republic of Laos shows 96\% of the transferred cases arrived at the district hospitals immediately, which is comparable to our study.

Despite being one of the poorest countries in the world, recent studies reported TB control in Afghanistan is manageable due to good collaboration and partnerships $[5,6]$. Of the 170 transfer-out patients, about $71 \%$ were transferred to the central polyclinic and Dashti Barchi health centres. Historically, these centres served as the main branches of the NTI and the NTI staff have established a good relationship with the staff over almost 10 years. Another possible reason for the high arrival rate could be the convenience of travel, especially to these 2 places.

Afghanistan is exceptional in that TB notification is higher in women and women's life expectancy is shorter [7]. This study reported a higher rate of transfer out among women. Several studies have shown that women experience more TB stigma and this results in higher default rates [8]. In this study, the arrival rate at the health centres by young women was similar to other age groups. Seeking care at the transfer facility might be the only option because women may not be able to afford private $\mathrm{TB}$ treatment. 
Male transfer-out patients aged 21-40 years had the highest risk for non-arrival and highest default rate. This is similar to another recent study conducted in Kabul city [9]. Men of working age did not arrive at the health centres because they may have been concerned about losing their job due to daily visiting health centres. To prevent non-arrival and default in this age group whenever transfer out takes place the providers should discuss the barriers with male patients of this age group.

Although the NTI transfer-out patients to 33 provinces, we know only of the situation of patients living in Kabul, and not for those in other provinces. If the security situation in the country improves, future studies may overcome the current study limitation.

\section{Acknowledgements}

The initial research proposal was developed during the 2010 Stop TB action training course held in Tokyo, organized by the Japan International Cooperation Agency (JICA), implemented by the Research Institute of Tuberculosis, Japan Anti-Tuberculosis Association (RIT/JATA), in collaboration with the World Health Organization, the United States Centers for Disease Control and Prevention, the International Union Against Tuberculosis and Lung Disease, and Médecins Sans Frontières. We appreciate Dr Mitsuo Isono, JICA's senior advisor for health for his technical advice and valuable unpublished literature.

Funding: Japan International Cooperation Agency.

Competing interests: None declared.

\section{References}

1. Treatment of tuberculosis: guidelines for national programmes, 4th ed. Geneva, World Health Organization, 2009 (WHO/ HTM/TB/2009.420)

2. Arnadottir T et al. Decentralizing tuberculosis treatment: follow-up of patients during the transitional period. International Journal of Tuberculosis and Lung Disease, 2002, 6:609-614.

3. Meijnen $\mathrm{S}$ et al. Outcome of patients with tuberculosis who transfer between reporting units in Malawi. International Journal of Tuberculosis and Lung Disease, 2002, 6:666-671.

4. Ottmani SE et al. Improving the quality of cohort analysis by incorporating treatment outcomes of 'transferred in' TB cases. International Journal of Tuberculosis and Lung Disease, 2007, 11:588-590.
5. Ahmadzai $\mathrm{H}$ et al. Scaling up TB DOTS in a fragile state: postconflict Afghanistan. International Journal of Tuberculosis and Lung Disease, 2008, 12:180-185.

6. Mauch $\vee$ et al. Structure and management of tuberculosis control programs in fragile states-Afghanistan, DR Congo, Haiti, Somalia. Health Policy, 2010, 96:118-127.

7. Women and men in Afghanistan: baseline statistics on gender. Kabul, Afghanistan, Ministry of Women's Affairs/United Nations Development Fund for Women, 2008.

8. Gender and health research: Gender in tuberculosis research. Geneva, World Health Organization, 2005.

9. Momand HH. High TB DOTS patients default in Kabul: how health system in Afghanistan can respond to this challenge? [MSc thesis]. Karachi, Pakistan, Department of Community Health Sciences, Aga Khan University, 2010. 